\title{
The Analysis of Trapped Volume in Gear Pump
}

\author{
Xiaoru Hao ${ }^{\mathrm{a}}$, Xiaojun Zhou ${ }^{\mathrm{b}}$ and Xiaoguang $\mathrm{Liu}^{\mathrm{c}}$ \\ School of Mechatronic Engineering and Automation, Shanghai University, Shanghai 200072, China \\ axiaoru408@126.com, b sdzhouxj@shu.edu.cn, cxiaoguangvisa@126.com
}

Keywords: External gear pump, tooth profile equations, trapped volume, mathematical model.

\begin{abstract}
The large pressure overshoots or spikes could be easily provoked by virtue of the rapid volumetric change in working process of gear pump, which cause the gear machines to be noise, vibration, strength and other problems, directly affect the stationarity and lifetime performance of the gear machine. For the purpose of this paper is to investigate the variation characteristics of trapped volume in the meshing process of external gear pump. Firstly, a complete mathematical equations of involute gear tooth profile is established after analysis of tooth profile structure with same design parameters on the driving and driven gears. Then, the mathematical model of trapped volume is proposed based upon the meshing theory and a complete set of mathematical equations of tooth profile. This model can accurately and effectively predict the volume of trapped fluid. Finally, the program edited by ourselves is used to solve the mathematical model in the Matlab environment. The results show that the variation curve of the trapped volume is parabola curve, and present symmetric distribution.
\end{abstract}

\section{Introduction}

Gear pump is one of the main hydraulic components, because of its low manufacturing cost, compact structure, high reliability, good performance and convenient maintenance, which widely used in the fields of automobile, light industry, chemical industry, shipbuilding and other industries. Depending on meshing form, there are two main different types of gear pumps: external and internal [1]. Compared with the internal gear pump, the external gear pump can convert mechanical energy into hydraulic energy with high pressure, and the structure is simple, that has a advantage in the less maintenance.

External gear pump usually has a certain displacement and the operation process is very simple. Which complete a certain fluid transport through two meshing gears rotating against each other. When gear teeth meshing with each other, it will form a closed cavity which separates suction side and discharge side, known as the trapped volume. The trapped volume of fluid with rapid change will lead to the pressure of trapped oil greater or less than the inlet pressure. When the pressure is too large, it is easily give rise to vibration and noise of gear pump and affect the gear mechanical stability and strength. On the other hand, the pressure is too small, which can result in cavitation. Therefore, the meshing action will produce the pressure pulsation of the trapped oil that are a critical dynamics affecting a system's lifetime performance.

In the literature, several authors addressed their studies on the gears' tooth form $[2,3]$, flow characteristics and the pressure ripples of external gear pumps. Most of them deal with pressure ripples occurring in regions of trapped volume during their working life, and some scientists focus on variation of trapped volume. Such as Foster [4] and Yanada [5] created a geometric formula of trapped volume. Lasri [6] developed a numerical model to calculate the control volume of the trapped fluid in the inter tooth. Above geometric formula was established according to the some design and operating parameters of gear tooth. Then, in this paper, the gear tooth profile model is used to analyze the variation of trapped volume. 


\section{Mathematical Model of Tooth Profile}

This section adopts involute tooth profile to calculate accurately the trapped volume of the external gear pump. A complete tooth file is composed of tip circle, involute and root fillet trochoid and root circle. The coordinate system of a symmetric involute tooth shape is shown in Fig. 1.

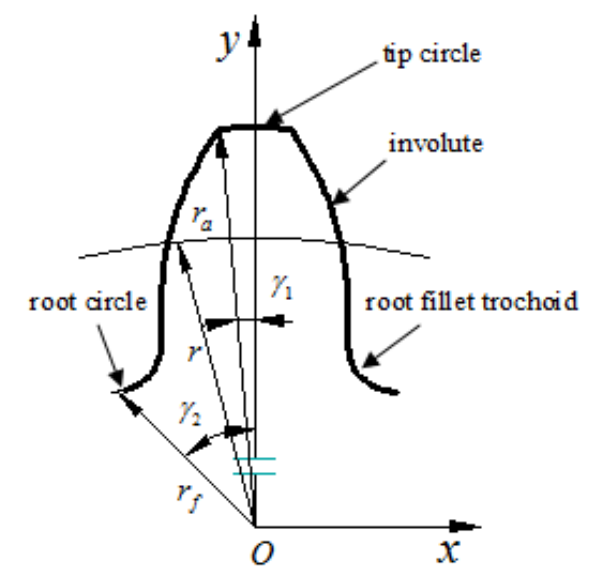

Fig. 1 Coordinate system for the involute tooth shape

In Fig. $1, r_{a}$ is tip circle radius, $r$ is pitch circle radius, $r_{f}$ is root circle radius, $\gamma_{1}$ is angle between radius of arbitrary point and $y$ axis on the tip circle, $\gamma_{2}$ is angle between radius of arbitrary point and $y$ axis on the root circle. The mathematical equations of tip circle and involute are expressed in reference [7]. This paper adopted the hobbing cutter as a rack cutter with two round edges, and the root fillet trochoid is the equidistant line of the prolate involute. Therefore, the equation for the root fillet trochoid on the end face can be written as [8]

$$
\begin{aligned}
& x=r \sin \varphi_{0}-\left(\frac{a_{1}}{\sin \alpha^{\prime}}+r_{\rho}\right) \cos \left(\alpha^{\prime}-\varphi_{0}\right) \\
& y=r \cos \varphi_{0}-\left(\frac{a_{1}}{\sin \alpha^{\prime}}+r_{\rho}\right) \sin \left(\alpha^{\prime}-\varphi_{0}\right)
\end{aligned}
$$

Where $\alpha^{\prime}$ is a parameter between $\alpha$ and $90^{\circ}$

$$
\varphi_{0}=\frac{1}{r}\left(a_{1} \cot \alpha^{\prime}+b\right), a_{1}=a_{0}-x_{3} m
$$

here $x_{3}$ is addendum modification, other parameters is explained in reference [8].

The equation of root circle is given by

$$
\begin{aligned}
& x=r_{f} \cos \gamma_{2} \\
& y=r_{f} \sin \gamma_{2}
\end{aligned}
$$

When the parameter $\alpha^{\prime}$ is equal to $90^{\circ}$, by applying it into Eq. (1) we can calculate the value of coordinates $\left(x_{f}, y_{f}\right)$. The range of $\gamma_{2}$ with $\arccos \left(x_{f} / r_{f}\right) \square 90^{\circ}-\pi / z$ is represented by Eq. (3) and Fig. 1.

\section{Mathematical Model of Trapped Volume}

The mathematical model for the complete tooth shape of involute gears can be obtained by the equations of tooth profiles. It is assumed that matrix $\left[x_{0}, y_{0}\right]^{T}$ is the mathematical model of one tooth profile, the driving gear mathematical model is expressed as

$$
\begin{aligned}
& x_{1}=\cos \theta x_{0}-\sin \theta y_{0} \\
& y_{1}=\sin \theta x_{0}+\cos \theta y_{0}
\end{aligned}
$$


Where $\theta=2 \pi \cdot n_{1} / z$ and $n_{1}$ takes positive integer that is in the range of $1 \leq n_{1} \leq z$. According to the kinematics of gear geometry and meshing theory, the driven gear equation in the Cartesian coordinate system can be written as

$$
\begin{aligned}
& x_{2}=x_{1} \cos \left(\varphi_{1}+\varphi_{2}\right)-y_{1} \sin \left(\varphi_{1}+\varphi_{2}\right)+a \sin \varphi_{2} \\
& y_{2}=x_{1} \sin \left(\varphi_{1}+\varphi_{2}\right)+y_{1} \cos \left(\varphi_{1}+\varphi_{2}\right)-a \cos \varphi_{2}
\end{aligned}
$$

The mathematical model of intersection area which is formed by driving gear and driven gear equations, that is the mathematical model of trapped volume. The main problem of this paper is to give a procedure to calculate coordinates value of intersection point by equations of the gear pairs. It is assumed that the functions of driving gear and driven gear can be expressed $f\left(x_{x}, y_{2}\right)$ and $f\left(x_{1} \cdot y_{1}\right)$ respectively, so the equation of trapped volume can be given as

$$
V=\int_{x_{1}}^{x_{2}}\left(f\left(x_{2}, y_{2}\right)-f\left(x_{1}, y_{1}\right)\right) d x
$$

Where $x_{1}$ and $x_{2}$ are the corresponding horizontal coordinate of the meshing point.

\section{Result and Analysis}

Using the mathematical method as in the previous sections, the variation curve of trapped volume with the rotation angle of gear can be obtained. A program written by the Matlab code is developed to plot the teeth profiles of gear pump and the curves of trapped volume, the case where the driving gear and the driven gear have the same parameters, for $z_{1}=z_{2}=10, m=3, \alpha=20^{\circ}, h_{a}^{*}=1, c^{*}=0.25$, $x_{3}=0$, where $z_{1}, z_{2}$ are the number teeth of driving and driven gears respectively. $m$ is module, $\alpha$ is pressure angle, $h_{a}^{*}$ is the addendum coefficient, $c^{*}$ is radial clearance coefficient, $x_{3}$ is addendum modification coefficient. The variation curves of trapped volume as shown in Fig. 2.

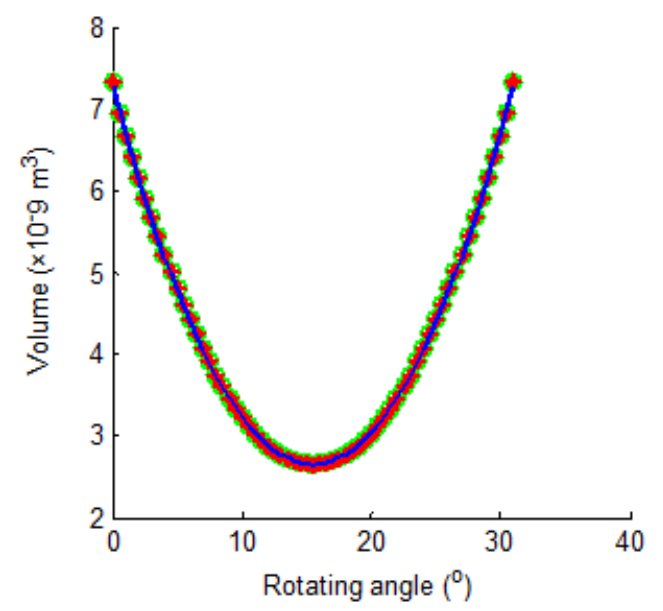

Fig. 2 The variation of trapped volume in external gear pump

As shown in Fig. 2, the variation curve of trapped volume has the parabola form, it is also shown that the variation curve form of trapped volume is symmetry distribution and have the peak value $7.3209 \times 10^{-6} \mathrm{~m}^{3}$, the trapped volume have the minimum value that is $2.7546 \times 10^{-6} \mathrm{~m}^{3}$ when then rotating angle equal to 15.6507 degree. In the working process of gear pump, the variation curves of trapped volume repeat the above course until the end.

\section{Conclusion}

The large pressure overshoots or spikes could be easily provoked by virtue of the rapid volumetric change in working process of gear pump, which cause the gear machines to be noise, vibration, strength and other problems, directly affect the stationarity and lifetime performance of the gear machine. For the purpose of this paper is to investigate the variation characteristics of trapped volume 
in the meshing process of external gear pump. Firstly, a complete mathematical equations of involute gear tooth profile is established after analysis of tooth profile structure with same design parameters on the driving and driven gears. Then, the mathematical model of trapped volume is proposed based upon the meshing theory and a complete set of mathematical equations of tooth profile. This model can accurately and effectively predict the volume of trapped fluid. Finally, the program edited by ourselves is used to solve the mathematical model in the Matlab environment. The variation curve of the trapped volume is parabola curve, and present symmetric distribution.

\section{References}

[1] J. Ivantysyn., M. Ivantysynova, Hydrostatic pumps and motors, Academia Books International, New Delhi, 2001.

[2] A.C. Radicella, G.D. Francesco, V.L. Battaglia et al, Procedure for the automatic mesh generation of innovative gear teeth, MATEC Web of Conferences. (2016) 1-6.

[3] S. Sankar, M. Nataraj, Profile modification - a design approach for increasing the tooth strength in spur gear, Int J. Adv Manuf Technol. 55 (2011) 1-10.

[4] K. Foster, R. Taylor and I.M. Bidhendi, Computer prediction of cyclic excitation sources for an external gear pump, Proc. Inst. Mech. Eng., Part C: Journal of Mechanical Engineering Science. 199 (1985) 175-180.

[5] H. Yanada, T. Ichikawa and Y. Itsuji, Study of the trapping of fluid in a gear pump, Proc. Inst. Mech. Eng., Part A: Power and Process Engineering. 201 (1987) 39-45.

[6] A. Lasri, F. Ville, L. Belfals and B. Najji, Preliminary modeling of the oil trapping between teeth for spur gears, Mechanics and Industry. 15(2014) 393-402.

[7] K. Nagamura, K. Ikejo and F.G. Tutulan, Design and performance of gear pumps with a non-involute tooth profile, Proc. IMechE Part B: Journal of Engineerin g Manufacture. 218 (2004) 699-711.

[8] T.J. Lin, H. Ou and R.F. Li, A finite element method for 3D static and dynamic contact/impact analysis of gear drives, Computer Methods in Applied Mechanics and Engineering. 196 (2007) 1716-1728. 